\title{
MANAGING WORKPLACE CONFLICT IN THE SCHOOL ENVIRONMENT: CHALLENGES, REWARDS AND THE WAY FORWARD
}

\section{Dramani Aminu and Charles Marfo}

\begin{abstract}
Conflict is a normal and natural part of our workplaces and lives. As people with diverse background come together in a working environment, differences in opinion, attitudes and beliefs are bound to occur as they interact. How such differences are managed determines the impact they can have on productivity and therefore organizational goals. Recognizing and addressing the factors that give rise to potential conflicts can have a positive impact on the workplace and productivity. Conflict, if constructively handled, can be very helpful in making necessary changes within the work environment. However, poorly resolved or unresolved conflict can result in feelings of dissatisfaction, unhappiness, hopelessness, depression, and other emotions. It can even lead to resignation from jobs, dissolution of personal relations, aggression, and even violence.
\end{abstract}

Key words: Conflict, Management and Workplace. 


\section{Introduction}

The phenomenon of workplace conflicts has become a worry to every organization. Indeed, if there is one thing derailing organizational goals in today's cooperate world, it must be workplace conflict. Conflict has been and will continue to be with us in all our endeavors. ${ }^{1}$ Unfortunately, engaging in dialogue and negotiation around conflict is something we tend to approach with fear and hesitation. We are often afraid that conversation (in course of resolving conflicts) will become worse than the conflict itself. We show predispositions when faced with conflict; some approach and others withdraw, some see opportunity in conflicts and others see destruction, some want to face and resolve but others want to win.

Whether a conflict will be a blessing or a curse to any individual, group or organization depends on how the problem is seen and managed. It is important to note that while unresolved or poorly resolved conflict can have devastating consequences on productivity, a well-managed workplace conflict can promote team work, efficiency and therefore increased productivity towards the realization of organizational goals. Here, we examined the nature of workplace conflict; factors that give rise to conflict in the workplace; how workplace conflict works; and how to harness it to produce positive results rather than a negative one or, better still, destruction. We also highlighted some of the likely challenges to resolving conflict and then made recommendations for minimizing or preventing conflict in the school environment. The specific questions addressed included the following: Are workplace conflicts necessarily evil? Are they inevitable? Is the management of workplace conflict a mere waste of time? Are they preventable? What are some of the challenges of managing conflict in the school environment?

\footnotetext{
${ }^{1}$ See some suitable definitions in the next section.
} 
To address the above concerns/questions, we divided the article into three sections. In the first section, we considered the nature, causes and symptoms of conflict in general and workplace conflict in particular. In the second section, we discussed the various management styles and challenges associated with them, and in the third and final section, we suggested the way forward, followed by a conclusion.

\section{The nature of conflict}

Like many other social science concepts, conflict does not submit itself to a single and widely accepted definition. Different authorities have given different definitions. Dougherty and Pfaltzgraff (1971: 139) defined the concept as:

a "condition in which one identifiable group of human beings is engaged in conscious opposition to one or more other identifiable human groups because the groups are pursing what are or appear to be incompatible goals".

Dougherty and Pfaltzgraff (1971: 139)

Dougherty and Pfaltzgraff's definition clearly points to the fact that conflict arises out of interaction between and among people. Wise (2000: 5) also defined conflict as "Two pieces of matter trying to occupy the same space at the same time". That is, conflict can also occur between two individuals in opposing positions on the same subject. For example, two individual members of staff of the same school or college, may be struggling to occupy a vacant position of a headmaster or a head of department, and hence the conflict. To Laue (1992: 10), conflict is an "escalated, natural competition between two or more parties about scarce resources, power and prestige; parties in conflict believe they have incompatible goals, and their aim is to neutralize, gain advantage over, injure or destroy one another. This clearly shows that "conflict implies 
more than mere competition” (Laue, 1992:10). It also brings out some of the valuables over which conflicting parties struggle. Such valuables could either be real or perceived; visible (such as computers, office space) or invisible (ones like power and prestige). Knowledge about values that can create conflict is important for effective resolution of any conflict, especially where the cause of the problem is psychological.

The second part of Laue's perception of conflict points out the destructive elements of conflict. To him, each party to a conflict aims at thwarting, injuring or destroying the other, in order to realize some goals regardless of the genuineness or otherwise of such goals. Though Laue makes us see why conflict must be resolved or prevented, the question is, is conflict always destructive?

Not all scholars of conflict perceive the concept in such pure negative terms. Oquaye (1995), Sawyerr (1997), Stedman (1991) and Blavo (1994), just to mention a few, did agree that conflict could be violent. In this case, violence is not an inherent aspect of conflict but rather a potential form that it may take (Stedman, 1991: 367-389). After all, as Sawyerr (1997: 1) noted, "not all conflicts are detrimental to human society”. In some cases, they (i.e. conflicts) give rise to innovation and progress. Stedman (1991: 367) observed that conflicts could be peaceful, and that such peaceful conflicts could be handled according to some laid-down mechanisms for pursuing competing interests. A workers' associations' or unions' [e.g. Ghana National Association of Teachers (GNAT) or Trade Union Congress (TUC))] demand for better conditions of service can be resolved through negotiating at a round table. Free and fair elections are all good examples of how conflicts could be resolved without recourse to violence. To Stedman, it is when all existing mechanisms for peaceful resolution of conflict fail or when parties go beyond seeking redress peacefully that conflict becomes pathological. 


\section{Inevitability of conflict}

Conflict is natural and an inevitable part of all human social relationship, and at all levels of society (Laue, 1992: 10). ${ }^{2}$ It must be emphasized that conflict has been part of civilization of the world since primordial periods. Pheuman and Bruehl (1982:3) defined conflict as that condition which is always present when two or more interdependent parties interact. Since human beings are, by nature, interdependent beings, and are in continuous interaction with one another, conflict will always exist. Increased interaction therefore, becomes an ingredient in the conflict mixture. The more often people interact (in the work environment), the more potential it is for conflict to arise.

Organizations, institutions (including educational institutions) are run by human beings, who are individuals with differences in their reasoning capabilities, emotions, experiences and values. So long as these differences remain and interactions among employees continue, workplace conflict will be inevitable. This is, however, not to say that the existence of differences automatically creates conflict. Rather they can be triggers.

\section{General causes of conflict}

Since time immemorial, resort to force has prompted efforts to understanding its causes. Kegley and Wittkopf (1994: 435) using the internal characteristic theory to explain why countries resort to violence, blamed it on leaders. To them, it is the choices leaders make that ultimately determine whether violence will occur or not. They explained further that, in making choices

\footnotetext{
${ }^{2}$ By natural we mean human beings are interdependent and in continuous interaction with one another, hence the inevitability of conflicts.
} 
about the use of force, however, the policy makers are influenced by certain characteristics of states. Based on this, they identified eight (internal) attributes that cause conflict. But for the purpose of this article we shall be concerned with two, namely (national) poverty and the type of leader (i.e. government).

With poverty, Kegley and Wittkopf (1994) argued that the level of economic development (wealth) affects the probability of involvement in conflict (violence). To them, aggression is a response to frustration and relative deprivation. Organizations and institutions of learning that are properly resourced are less likely to have its members resort to violence conflict that might risk that valued status. Both staff and students of well endowed schools feel more confident and motivated to teach and learn than their counterparts in less endowed schools. Thus, when people's expectations of what they deserve rise more rapidly than their material rewards, the probability of conflict grows.

On the type of leader (government), Kegley and Wittkopf (1994) postulated that when a leader has imbibed democratic values (or any acceptable form of governance), it is less likely for him to resort to the use of force. Particularly, it is believed that democracy inhibits the frequency with which disputes are settled by force. Applying this to workplace conflict, where the leader of an institution (e.g. Headmaster/Head teacher, Vice-Chancellor) has democratic values, he/she will respect the opinions of others as well as democratic channels that exist for nonviolent resolution of differences. Moreover, in a democratic environment, rules and regulations limit leaders' freedom, and encourage active participation and liberties (such as freedom of speech, opposition, criticism) thereby reducing the tendency of using violent means to resolve differences. 


\section{Sources of conflicts in the school environment}

Workplace conflict may be shaped by the unique aspects of its occurrence at the workplace, including the long hours of work, high workload, and the hierarchical structure of the organization. In this respect, workplaces share much in common with schools, especially precollege educational institutions. Among the common sources of workplace conflicts are:

i. Unclear definition of responsibility: Where this is the case, there will be numerous occasions for conflict to arise over decisions made or actions taken in disputed territory.

ii. Lack of/Limited Resources: Time, money, space, materials, supplies and equipment are all valuable resources. Competition for any of these resources will inevitably lead to interpersonal and interdepartmental conflict.

iii. Conflict of interest: Individuals may fight for their personal goals and lose sight of organizational goals. The breeding ground for conflict may lie in confusion about, or disagreement with, the common purpose and how to achieve it while also achieving individual goals within an organization.

iv. Poor/Lack of open communication: Communication is a cause of conflict and a remedy as well. Poor or lack of open communication drives conflict underground and can create a downward spiral of misunderstanding and hostility.

v. Interdependency: Interdependence within institution feeds conflict. Our ability to accomplish our goals and objectives depends on the cooperation and assistance of others, but this increases the opportunity for conflict. When the other person is late, has different priorities, misunderstands directions, or is playing office politics, conflicts are created. 
vi. Workplace romance: Public displays of affection can make co-workers uncomfortable and accusations of favoritism may occur, especially if it is a superior-subordinate relationship; e.g. Headmaster-Housemistress relationship. If the relationship gets awry, one party may seek to exact revenge on the other (Rau-Foster, 2000).

vii. Perception: Perception, i.e. a particular way of regarding, understanding or interpreting something, is fundamentally individual to each person. Often, people will have divergent perceptions of an issue based on their suspicion, level of trust, assumptions, expectations, experience and history. Workplace conflicts "operate parasitically within an environment characterized by low trust and suspicion...” (Beardwell and Holden, 1997: 569), characters very common among teachers.

Besides the above, the following sources of conflict are more peculiar to the pre-college educational institutions in Ghana.

i. Jealousy: Normally, people are recruited into institutions with differences in levels of education. Therefore, they occupy different positions. However, perceptions, assumptions and expectations combine to turn this normal situation into jealousy, which then results in conflict between and among teachers.

ii. Discrimination: When heads, supervisors, etc. discriminate against subordinates, grounds are prepared for conflicts to arise. Such conflicts are severe when the discrimination is along tribal or religious lines.

iii. Unfair disbursement of revenue generated from extra classes. 
iv. Load sharing: When people realize that their workloads are heavy while colleagues of equal qualification have less, there is the tendency of creation of pressure and stressful situations. And when this is not managed, conflicts are bound to occur.

\section{The good in workplace conflict}

To those who fear conflict and see it as something that must always be avoided, workplace conflict has nothing good to offer. But those who see conflict as normal and natural part of human lives, both professionally and personally, think of it as opportunity. Blavo (1994) noted the existence of negative elements in conflict, but also argued that conflict contains some positive elements as well. As he puts it "conflict contains something positive. It is a way of achieving some kind of unity ... conflict itself resolves the tension between contrasts” (Blavo, 1994: 47). Thus, if conflicts are properly handled, they could impact positively on productivity in the workplace. Among such positives/benefits of workplace conflicts are:

Stimulation of interest and curiosity: The functional view of organizational conflict sees conflict as a productive force; one that can make members of an organization curious and stimulate them to increase their knowledge and skills, and their contribution to organizational innovation and productivity.

Feedback: Conflict provides people with feedback about how things are going. It enables a person to become aware of problems in a relationship. It could also carry information to the supervisor/manager about what is not working in an organization, affording the opportunity to improve. 
Motivation: Conflict may also motivate and/or energize to deal with immediate problems. It is possible that the very differences that create conflict can at times provide the spark which energizes the team and triggers productive benefits such as enhanced creativity, innovation and efficiency.

Relieving Tension: Conflict relieves minor tensions. It gets hidden feelings out in the open where they can be dealt with by all parties concerned. This moves relationships out of the rut and promotes genuine interaction among people.

Catalyst to Change: Workplace conflict serves as catalyst for positive change; it promotes selfknowledge and causes decisions to be made more carefully. It also clears the air of unexpressed resentments and thereby develops confidence in relationships.

We observe, however, that unresolved or poorly managed conflict comes with its own costs. It can lead to confusion, refusal to cooperate, missed deadlines, increased stress among employees, reduced creative collaborations and team problem solving, disrupts workflow, distrust, split camps, gossip and discrimination. When a personalized conflict is not turned into substantive one, it can result in violence.

\section{Management styles}

If a person subscribes to a flexible vision of effective organization, and recognizes that each conflict provides opportunity to improve, they would shift their view of conflict. Rather than trying to eliminate conflict, or suppress its symptoms, their task becomes managing conflict so that it enhances people and organizations, rather than destroying them. In managing workplace conflicts, following Johnson (1990: 3-5), five (5) different conflict management styles can be 
employed and they are explained as follows. It is important to note however, that effective conflict management involves not only knowing when to use each style, but also having skills and experience.

Competing: Competing has variously been linked to sharks and has been explained that, by nature, sharks have the need to win. This means that others must lose (win-lose situations). Thus, this is a forcing or competing conflict management style; it does not hesitate to use aggressive behavior to resolve conflicts. One can then say that it can be autocratic, authoritative, uncooperative, threatening and intimidating. It gives low priority to relationships and it is highly goal oriented. This style is appropriate in several situations including when conflict involves personal differences that are difficult to change, when fostering intimate or supportive relationships is not critical, when others are likely to take advantage of noncompetitive behavior, when conflict resolution is urgent, when decision is vital in crisis, and when unpopular decisions need to be implemented.

The advantage with this style is that if the shark's decision is correct, a better decision without compromise can result. However, the person using it may breed hostility and resentment toward him/herself, and that is a disadvantage.

Avoiding: Turtles adopt an avoiding or withdrawal conflict management style and so they have been linked with avoiding. They would rather hide and ignore conflict than resolve it; they are therefore uncooperative and unassertive. Turtles tend to give up personal goals and display passive behavior creating lose-lose situations. However, it is appropriate where one of the following is the case: the stakes are high or issue trivial, confrontation will hurt a working relationship, there is little chance of satisfying your wants, disruption outweighs benefits of 
conflict resolution, gathering information is more important than an immediate decision, and others can more effectively resolve the conflict.

The strength of the avoiding turtle style is that it may help maintain relationships that would be hurt by conflict resolution. The weakness of the style is that conflicts remain unresolved, its over use leads to others walking over them (users of this style).

Accommodating: Described as a trait of the teddy bear, with this style, smoothing or accommodating conflict management style with emphasis on human relationships is used. This is the advantage of this style. But here, own goals are ignored and conflict is resolved by giving in to others; a disadvantage that describes the user as unassertive and cooperative, a situation that creates a win-lose situation.

Accommodating, however, is appropriate where maintaining the relation is much more important than other considerations; suggestions/changes are not important to the accommodator; time is limited or when harmony and stability are valued, among others.

Compromising: Fox-alike people take compromise position in conflict management and are concerned with goals and relationships and this is a hallmark advantage. A compromise however may create less than ideal outcome and game playing can result. They are also willing to sacrifice some of their goals while persuading others to give up part of theirs. They are assertive and cooperating, creating a win-lose or lose situation. This style is necessary when important/complex issues leave no clear or simple solution; all conflicting people are equal in power and have strong interests in different solutions; there are no time restraints. 
Collaborating: This is attributed to the owl for its collaborating or problem confronting nature. Using this style involves viewing conflicts as problems to be solved and finding solutions agreeable to all sides (i.e. win-win). Indeed, the use of this style is appropriate when there is the need to maintain relationships, time is not a concern, peer conflict is involved, trying to gain commitment through consensus building, and learning and trying to merge differing perspectives. The style has the advantage of creating a situation where both parties get what they want and negative feelings eliminated. However, it requires a great deal of time and efforts. In a school environment, the collaborative style is very helpful and therefore would like to go further.

\section{Challenges to conflict resolution}

Effective supervisors appreciate the importance of conflict resolution skills and demonstrate them regularly in the workplace. But these do not come without challenges. Some of these challenges are as follows.

1. One may be just uncomfortable with confrontation as anyone else, yet one is a role model for staff and has to be resilient in the resolution.

2. The contagious nature of conflict poses yet another challenge to the manager. The stress of the dispute can reach the whole department, work unit or the entire organization.

3. Pride is yet another difficulty. Where a written apology is what is required to resolve a conflict, for instance, headmaster may find it very difficult to apologize to a security man.

4. The 'I've been here for a long time' syndrome could create personalized conflict.

5. There is also the problem of dealing with difficult people; people who are just not prepared for any form of peaceful resolution, which falls short of what they desire. 


\section{The way forward}

While it is true that conflict cannot be eliminated from any human society, it can be minimized to the barest if appropriate steps are taken and measures put in place. As a beginning, the government, the private sector, and all other stakeholders in the sector should commit resources into conflict resolution training for heads and supervisors of our educational institutions. The expenditure of valuable resources to address and resolve conflict and to improve communication in schools in particular and workplaces in general may seem to be a luxury, but it is not. It is however, an effective measure to preserve the most important resources - happy and productive employees. “An investment in educating employees in effective communication and conflict resolution skills is a gift that keeps giving” (Rau-Foster, 2000: 3). Resources should be committed into training heads of schools, heads of department, as well as the other supervisors. Such a training will not only help them understand their relationship with conflict, learn strategies for resolving conflict with peers, and the ability to manage conflict between employees but also, to improve their communication, criticism and anger management skills. Education, after all is cheaper than ignorance.

There is the need to invest in a curriculum that supports teaching conflict and conflict resolution, especially in the teacher training institutions. It must be realized that conflict resolution, when taught as an invaluable life skill, is a viable tool for reforming hostile school environment. Further, trainees will not only have the ability to, the urge, and the passion for preventing and resolving conflicts, but also come to take the view that conflict situations are essentially 
bargaining situations. Viewing conflict behavior as a bargaining process is useful in keeping us from becoming exclusively preoccupied either with the conflict or with the common interest.

Employee handbook is yet another thing worthy of consideration by educational institutions. A well-written employee handbook can communicate employer expectations to employees and actually improve employee morale. It should set forth in detail the benefits, policies, and disciplinary rules of the institution and should be updated periodically. Relying on verbal communication is not very professional and it can give rise to confusion, conflict, and charges of discrimination or unfair treatment. This is not to say that employee handbook should replace personal communication; it is just a basic tool that can help.

One thing many schools (churches, mosques and other communal units) in Ghana do not have is counseling units. Where they exist, they are managed by unqualified persons. Where there are qualified personnel, the units are considered as meant for students only. The establishment of functioning and effective counseling units in schools, administered by professionals or well trained counselors, guided by ethical standards, could go a long way to ease tension among staff and thereby minimize conflicts and create safe school environment.

It is very important that heads of schools avoid the use of negative strategies such as non-action, administrative orbiting, secrecy, and meeting separately with people in conflict. Also, in the disbursement of resources such as cars, office space, accommodation, among others, there is the need to avoid deprivation and discrimination. Deprivation and discrimination lead to the feeling of frustration, rejection anger and revolt. If our schools could reduce vagueness, minimize authority - and domain - related disputes, improve policies and rules, and re-apportion existing resources, conflict will be prevented or resolved. Activities such as football games and end of 
year get together can help promote the feeling of togetherness and oneness towards organizational goals. It will also help the staff to know each other very well. Relaxed atmosphere promotes free interaction.

\section{Summary and conclusion}

We have discussed the problem of workplace conflict and examined the nature of the phenomenon, symptoms, causes and consequences. For managing conflicts in schools, five different styles, namely, competing, avoiding, accommodating, compromising and collaborating, were also explained, bringing out clearly when each can be used as well as their strengths and weaknesses. A number of likely challenges were also highlighted, along with a number of recommendations to minimize workplace conflicts and reap the benefits therein.

Ultimately, we suggest that conflict is inevitable in all human endeavors and it conflict could be looked at positively. In this case, conflict is not necessarily detrimental to organizational goals. But, it all depends on who is managing the conflict and how well it is managed. With skills and experience, different management styles can be taken advantage of to turn what would have been destructive to productive.

\section{References}

Beardwell, I and L. Holden (1997). Human resource Management: A Contemporary Perspective ( $2^{\text {nd }}$ edition), London: Pitman Publishing.

Blavo, W. Q. (1994). National Boundaries, Migration and Refuges. In Conflicts in Africa, Vol. XXXII (Proceedings of the Ghana Academy and Sciences).

Concise Oxford Dictionary (10 ${ }^{\text {th }}$ edition) (1999), Oxford: University Press. 
De Cenzo, D. A. and S. P. Robbins (1994). Human Resource Management: Concepts and Practices, ( $4^{\text {th }}$ edition), New York: John Wiley and Sons Inc.

Dougherty, James E. and Roberty L. Pfatzgraff Jr. (1971). Contending Theories of International Relations, Philadelphia: J. B. Lippincott Company.

Flynn, Leslie B. (1988). When the Saints Come Storming in, Wheaton IL: Victor Books.

Kegley, W. Charles Jr. and Eugene R. Wittkopf (1994). World Politics: Trend and Transformation, Bedford: St Martins.

Laue, James (1992). “The Emergence and Institutionalization of Third Party Roles in Conflicts”.

In Dannis J. D. Sandole and Ingrid Sandole-Staroste (eds.); Conflict Management and Problem Solving: Interpersonal to International Applications, New York: New York Press.

Managing People, ACCA study Text paper 1.3, June 2004

Oquaye, Mike (1995). "Politics, Society and Conflict in Africa - An Overview". In Mike Oquaye (ed), Democracy and Conflict Resolution in Ghana, Accra: Gold Type Publication Ltd.

Pheuman, Roy W. and Margaret E. Bruehl. (1982). Managing Conflict, Englewood Cliffs, New Jersey: Prentice Hall.

Rau-Foster, Mary (2000) "Conflict in the Workplace", http://www.workplaceissues.com/areconflict.htm,

http://webhome.idirect.com/ kehamitt/ipsyconf.html

Sawyerr, Amos (1997). Dynamics of Conflictment in Liberia, Accra: Institute of Economic Affairs Publication. 
Stedman, Steven J. (1991). "Conflict and Conflict Resolution: A Conceptual Framework”. In Francis M. Deng and William I. Zartman (eds.), Conflict Resolution in Africa, Washington D.C.: The Brooking Institution.

Wise, Terry (2000). Conflict in the Church: Workbook, Trinity College and Seminary. 